\title{
CONF-970486--1
}

\section{CHARACTERIZATION OF SEGREGATION IN NICKEL AND TITANIUM ALUMINIDES}

\author{
M.K. Miller, D. J. Larson and K.F. Russell \\ Metals and Ceramics Division, \\ Oak Ridge National Laboratory, \\ Oak Ridge, TN 37831-6376, USA
}

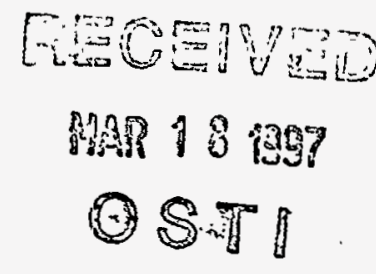

\section{Abstract}

Atom probe field ion microscopy has been used to characterize the distributions of microalloying additions in the microstructure of a variety of nickel and titanium aluminides. In $\mathrm{Ni}_{3} \mathrm{Al}$, boron additions were found to segregate to dislocations, low angle boundaries. stacking faults, antiphase boundaries, and grain boundaries. The boron and aluminum levels at grain boundaries were found to vary both from boundary to boundary and also along an individual boundary segment. In some cases, a boron-enriched film up to $-3 \mathrm{~nm}$ thick was observed. In aluminum-enriched $\mathrm{Ni}_{3} \mathrm{Al}$, ultrafine clusters containing up to approximately 10 boron atoms were detected in the matrix.

In contrast, the majority of the boron additions in NiAl was determined to be in the form of ultrafine $M_{2}$-type precipitates. These precipitates offset the benefits of the boron segregation to the high angle grain boundaries. In molybdenum-doped $\mathrm{NiAl}$, atom probe analyses indicated extremely low solubilities of the molybdenum and other trace impurities in the matrix and significant enrichments of molybdenum, nitrogen and silicon, boron, and iron at the grain boundaries.

In boron-doped two phase $\alpha_{2}+\gamma$ TiAl containing chromium, niobium, and tungsten, the boron level was found to be significantly depleted from the bulk level in both the $\alpha_{2}$ and $\gamma$ phases and a variety of coarse borides including $\mathrm{TiB}, \mathrm{TiB}_{2}$ and a finer chromium-enriched (Ti, $\left.\mathrm{Cr}\right)_{2} \mathrm{~B}$ precipitate was observed. The tungsten and chromium were determined to partition preferentially to the $\alpha_{2}$ phase and also to segregate to the $\alpha_{2}-\gamma$ and $\gamma-\gamma$ interfaces. These results indicate that a significant proportion of the microalloying elements are consumed by the boride precipitates.
Introduction

Nickel and titanium aluminides have attractive potential for technological applications due to their superior high temperature properties. However, the brittleness of these materials at room temperature makes fabrication difficult and therefore limits their application. One of the traditional methods of improving the properties of these types of materials is to add microalloying elements.

A variety of microalloying elements including boron and molybdenum have been used to improve the mechanical properties of both $\mathrm{Ni}_{3} \mathrm{Al}$ and $\mathrm{NiAl}$. Boron additions to the $\mathrm{Ll}_{2}$-ordered $\mathrm{Ni}_{3} \mathrm{Al}$ of as little as 200 parts per million produce dramatic improvements in ductility [1,2]. However, boron additions to the B2-ordered NiAl have a significantly different effect on the microstructure and the mechanical properties [3]. Although additions of as little as $\mathbf{2 0}$ parts per million of boron improve the ductility, larger amounts significantly increase the yield strength. The addition of between 0.4 and $1.6 \%$ molybdenum to $\mathrm{NiAl}$ has been shown to significantly improve the room temperature ductility and high temperature yield strength [4].

Efforts to enhance the ductility and refine the grain size in TiAl-based materials have focused on the addition of a variety of microalloying elements such as boron, silicon, tungsten, chromium, vanadium, manganese and molybdenum [5]. Boron additions of greater than -0.5 at. \% are effective in refining the grain size in cast materials $[5,6]$ and additions at the level of only a few hundred parts per million have been shown to refine and stabilize the lamellar structure in $\gamma$-based TiAl alloys [7-10]. Tungsten additions to TiAl enhance oxidation resistance and improve creep resistance and strength whereas chromium additions enhance the ductility. However, the exact mechanism by which these

-The submitted manuscript has been authored by a contractor of the U.S. Government under contract No. DE-AC05-960P22464. Accordingly, the U.S. Government retains a nonexclusive, royalty-free license to publish or reproduce the published form of this contribution, or allow others to do so, for U.S. Government purposes." 
refinements are accomplished for these various elements is not understood [11]. In order to understand these mechanisms, one of the first requirements is to determine the distribution of these, microalloying additions in the microstructure.

The atom probe field ion microscope (APFIM) is well suited to the characterization of the segregation and partitioning behavior of the microalloying elements in the microstructure due to its near atomic spatial resolution, light element sensitivity, high mass resolution, and low detection levels $[12,13]$. These atom probe characterizations have focused on the quantification of the solubility levels of the microalloying elements in the matrix, the estimation of the levels of segregants at grain boundaries and other interfaces, and the determination of the size and composition of precipitates. This approach is required to determine the actual distribution of the microalloying elements in the microstructure so that their effectiveness may be more thoroughly evaluated.

\section{Experimental}

Atom probe field ion microscopy analyses were performed in the Oak Ridge National Laboratory energy-compensated atom probe field ion microscope [14]. Field ion specimens of these materials were produced by standard electropolishing procedures of either material cut from bulk samples or, in the case of $\mathrm{Ni}_{3} \mathrm{Al}$, wires produced by rapid solidification techniques [12]. The field ion micrographs were recorded with the use of neon as the imaging gas. Due to the low probability of randomly encountering some of these microstructural features in the atom probe, some field ion specimens were initially screened in the transmission electron microscope and suitable specimens were then selected for examination in the atom probe. This pre-selection process also provided additional information as to the precise nature of the defect. The compositions of the matrix and the precipitates were determined by selected aren atom probe analysis. Experimental conditions were chosen to prevent systematic errors due to preferential evaporation and retention of any solute.

In the case of grain boundary segregation. the solure coverage may be fundamentally determined with a method based on the Gibbsian interfacial excess. The Gibbsian interfacial excess $[15,16]$ of element $i$, $\Gamma_{i}$, is defined as

$$
\Gamma_{i}=\frac{\left.N_{i} \text { excess }\right)}{A}=\frac{N_{i}-N_{i}(\alpha)^{-} N_{i}(\beta)}{A},
$$

where $N_{i}$ (excess) is the excess number of solute atoms associated with the interface, $A$ is the interfacial area over which the interfacial excess is determined, $N_{i}$ is total number of solute atoms in the volume analyzed, $\mathrm{N}_{\mathrm{i}(\alpha)}$ and $\mathrm{N}_{\mathrm{i}}(\beta)$, are the number of solute atoms in the two adjoining regions $\alpha$ and $\beta$ either side of the dividing surface. The interfacial aren A that is sampled in a typical atom probe experiment is given by $A=\pi$ $r_{1}{ }^{2} / \cos \phi$, where $r_{a}$ is the effective radius of the probe aperture and $\phi$ is the angle between the unit normal to the interface plane and the unit vector parallel to the cylinder of analysis $\left(\phi \neq 90^{\circ}\right)$ and is determined from either the projection of the interface in the field ion micrographs or examination of the field ion specimen in the transmission electron microscope. The actual number of atoms collected must take account of the less than perfect detection efficiency of the single atom detector. The detection efficiency of the atom probe used in these investigations has been determined to be 0.62 . The interfacial excess can be related to the fractional monolayer coverage of solute, $\Phi$, by comparing it to the saturation value of the excess, $\Gamma_{i}($ sat $)$, i.e., $\Phi=\Gamma_{i} \Gamma_{i(s a t)}$. There are a number of interpretations of what constitutes a monolayer [17]. The method used in this paper was based on the number of atoms expected on the closest packed plane of the crystal structure. For example, in $\mathrm{NiAl}$ this is the $(110)$ plane and therefore a monolayer coverage consists of $1.72 \times 10^{19}$ atoms $\mathrm{m}^{-2}$ with a width $\mathrm{w}=\mathrm{d}(110)=0.20 \mathrm{~nm}$.

\section{Results and Discussion}

\section{$\underline{\mathrm{Ni}_{3} \mathrm{Al}}$}

In boron-doped $\mathrm{Ni}_{3} \mathrm{Al}$, atom probe analysis revealed that most of the boron addition remained in solid solution in the matrix. In addition, field ion microscopy revealed that boron was found to segregate to dislocations, Fig. 1, low angle boundaries, Fig. 2, stacking faults (SISF), Fig. 3, antiphase boundaries. Fig. 4, and grain boundaries Figs. 5 and 6 [18-21]. All the dislocations and boundaries shown in these field ion micrographs are decorated with brightly-imaging spots. The unique single atom identification capability of the atom probe was used to determine that these brightly-imaging spots are individual boron atoms. In the cases of the low angle boundary and the stacking fault, the boron decoration is more clearly revealed in field ion micrographs that were taken during field evaporation, shown in Figs. $2 \mathrm{~b}$ and $3 \mathrm{~b}$, since the contrast due to the individual atomic terraces (i.e., the concentric rings) is minimized rendering the brightly-imaging boron atoms more prominent. It is evident from the narrow width of the segregation exhibited in these field ion micrographs that the boron segregation is confined to the interface plane. Boron segregation to the dislocations, low angle boundaries, stacking faults and antiphase boundaries should influence the mechanical properties through a solute drag type mechanism.

A pair of field ion micrographs of two different grain boundaries is shown in Fig. 5. It is evident from the distribution of the brightly-imaging atoms in the field ion micrographs that the boron coverage at the grain boundaries varies significantly. This variation was also observed along different regions of the same grain boundary as shown in Fig. 6. For example, in some regions the coverage was extremely low, e.g., Figs. 6 a and $6 \mathrm{~d}$, whereas in other regions there was significantly higher coverage, e.g., Fig. $6 c$ and $6 \mathrm{e}$. Atom probe quantification of the boron level and the nickel to aluminum ratio at two grain boundaries is summarized in Table 1 . In addition the local solute distribution along a single grain boundary is shown. The boron coverage along this grain boundary was found to vary from over a significant range of 9.4 to $61.9 \%$. Similar wide variations have been observed at other grain boundaries. The Ni:Al ratio was found to vary from 2.2 to 3.4 . It should be noted that the Ni:Al ratio of the matrix in these aluminum-depleted materials was 3.1. No simple correlation between the $\mathrm{Ni}$ :Al ratio and the boron coverage was found.

Table 1. The Gibbs interfacial excesses of boron at grain boundaries in $\mathrm{Ni}_{3} \mathrm{Al}$.

\begin{tabular}{|c|c|c|c|}
\hline Analysis & $\begin{array}{c}\text { Ni:Al } \\
\text { Ratio }\end{array}$ & $\begin{array}{c}\text { Gibbs Interfacial } \\
\text { Excess. } \Gamma_{i} \text { atoms } \text { m }^{-2}\end{array}$ & $\begin{array}{c}\text { Coverage } \\
\%\end{array}$ \\
\hline la & 3.40 & $4.5 \times 10^{18}$ & 26.7 \\
lb & 2.92 & $4.2 \times 10^{18}$ & 24.0 \\
lc & 2.23 & $4.8 \times 10^{18}$ & 27.0 \\
ld & 2.30 & $1.7 \times 10^{18}$ & 9.4 \\
le & 2.81 & $3.6 \times 10^{18}$ & 20.4 \\
lf & 2.70 & $1.1 \times 10^{19}$ & 61.9 \\
1 (avg.) & 2.73 & $5.0 \times 10^{18}$ & 28.2 \\
2 (avg.) & 2.73 & $2.3 \times 10^{18}$ & 13.0 \\
\hline
\end{tabular}

Some grain boundaries exhibited evidence of more extensive boron segregation, as shown in Fig. 7. In most cases, the boron segregation appeared as extended brightly-imaging lenticular regions at the grain boundary. The maximum thickness of these regions was estimated to be $-3 \mathrm{~nm}$ and their length was often larger than the field-of-view of the image, i.e., greater than $-100 \mathrm{~nm}$. The composition of these regions was determined to be $26-31$ at. \% $\mathrm{Al}$ and up to 5 at. \% B. Although the possibility of multilayer segregation cannot be totally excluded. it is more likely that this boron-enriched region is an ultrathin precipitate or grain boundary film. However, the measured composition does not appear to be consistent with the tau phase (nickel-aluminum-boride).

In addition to this extended morphology, some shorter (5 to $10 \mathrm{~nm}$ in length) boron-enriched regions were also observed, as shown in Figs. 7b and 7c. Most of the segment of the grain boundary shown in Fig. $7 \mathrm{~b}$ exhibited low coverage with only an isolated boron atom evident. However, a small facet that exhibited significantly higher boron coverage was also observed on this grain boundary. This observation indicates that the local boundary plane can have a strong influence on the segregation behavior. These smaller boron-enriched regions were also observed to be located preferentially on one side of the grain boundary as shown in Fig. 7c. It should be noted the absence of rings in 


\section{DISCLATMER}

Portions of this document may: be illegible: in electronic:image: products: Jimages are: produced from the best available original: document. 


\section{DISCLATMER}

This report was prepared as an account of work sponsored by an agency of the United States Government. Neither the United States Government nor any agency thereof, nor any of their employees, make any warranty, express or implied, or assumes any legal liability or responsibility for the accuracy, completeness, or usefulness of any information, apparatus, product, or process disclosed, or represents that its use would not infringe privately owned rights. Reference herein to any specific commercial product, process, or service by trade name, trademark, manufacturer, or otherwise does not necessarily constitute or imply its endorsement, recommendation, or favoring by the United States Government or any agency thereof. The views and opinions of authors expressed herein do not necessarily state or reflect those of the United States Government or any agency thereof. 


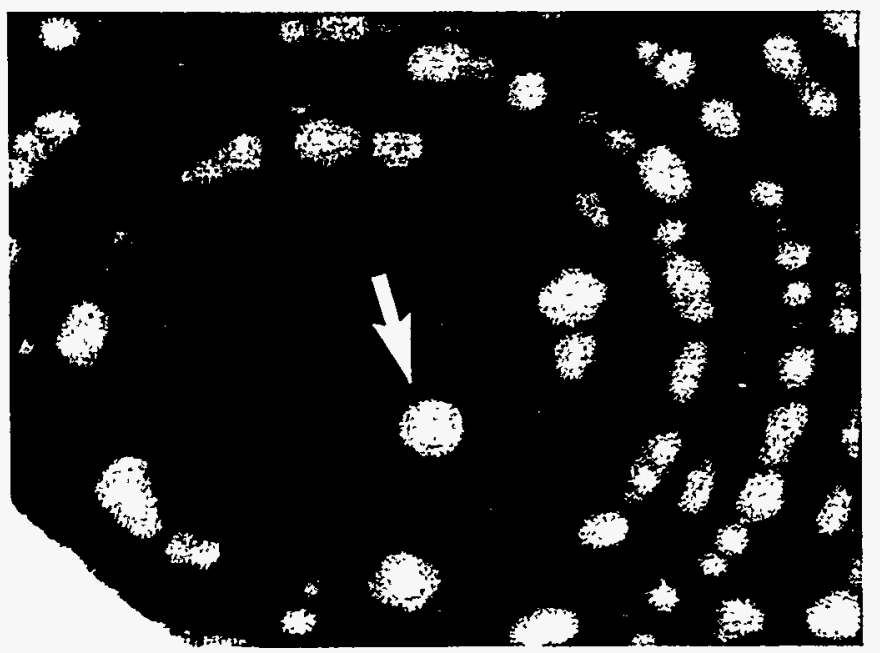

Fig. 1. Field ion micrograph of a boron-decorated dislocation in $\mathrm{Ni}_{3} \mathrm{Al}$.

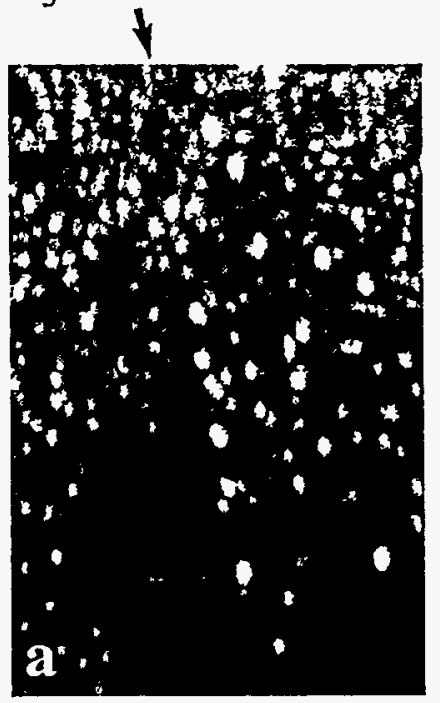

1

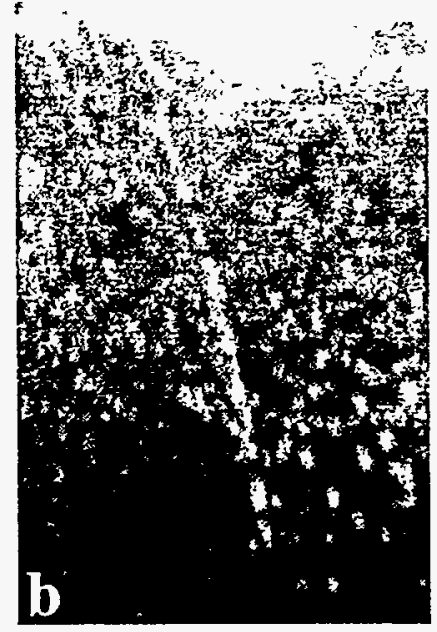

Fig. 2. Field ion micrograph of a boron-decorated low angle boundary (misorientation $<^{\circ}$ ) in $\mathrm{Ni}_{3} \mathrm{Al}$.

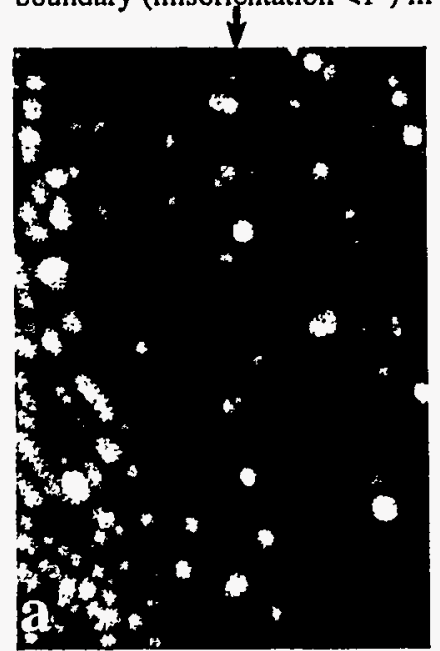

A

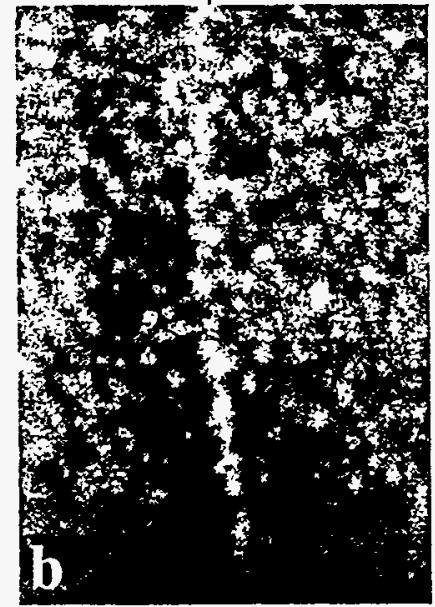

Fig. 3. Field ion mtcrograph of a boron-decorated stacking fault in cold worked $\mathrm{Ni}_{3} \mathrm{Al}$ annealed for $1 \mathrm{~h}$ at $800^{\circ} \mathrm{C}$.

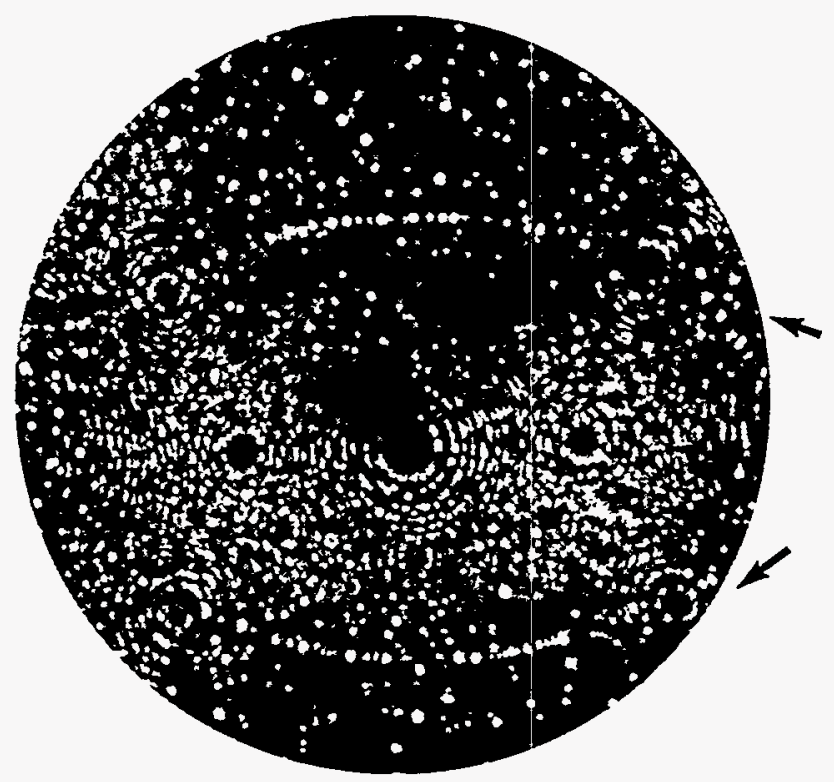

Fig. 4. Field ion micrograph of a boron-decorated antiphase boundary in $\mathrm{Ni}_{3} \mathrm{Al}$.
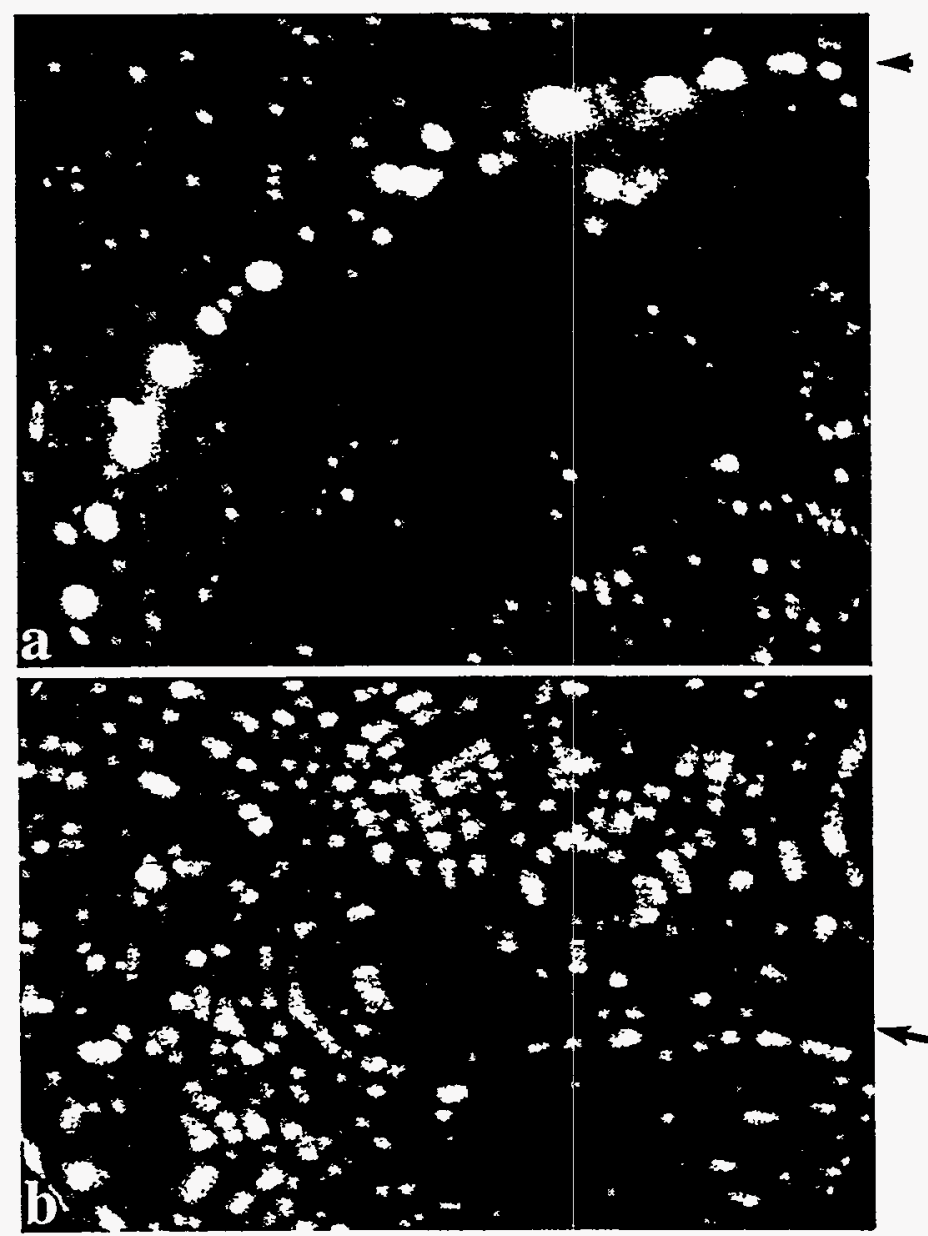

Fig. 5. Field ion micrographs of boron-decorated grain boundaries in $\mathrm{Ni}_{3} \mathrm{Al}$. 
${ }^{1}{ }^{1} \varepsilon_{\text {IN }}$ u!

$9 \tau^{1 \forall} \forall L_{1 N}(q)$

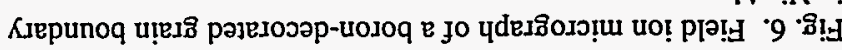

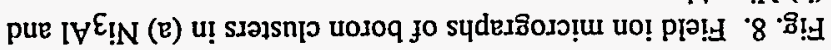

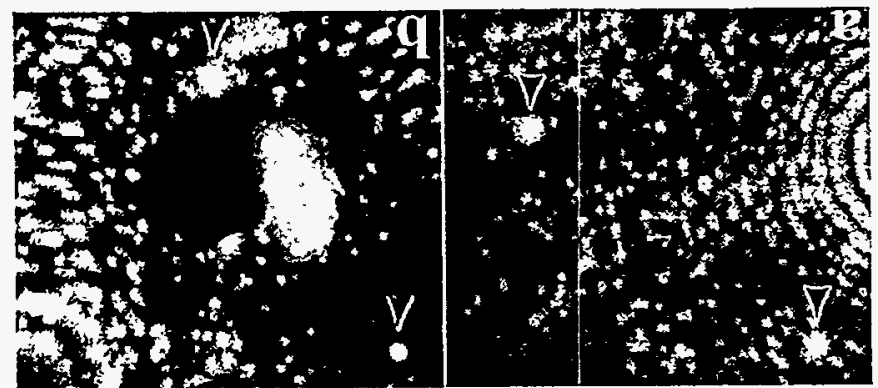

${ }_{1}{ }^{1} \varepsilon_{\text {IN }}$ u! əseपd

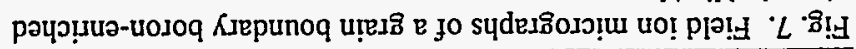

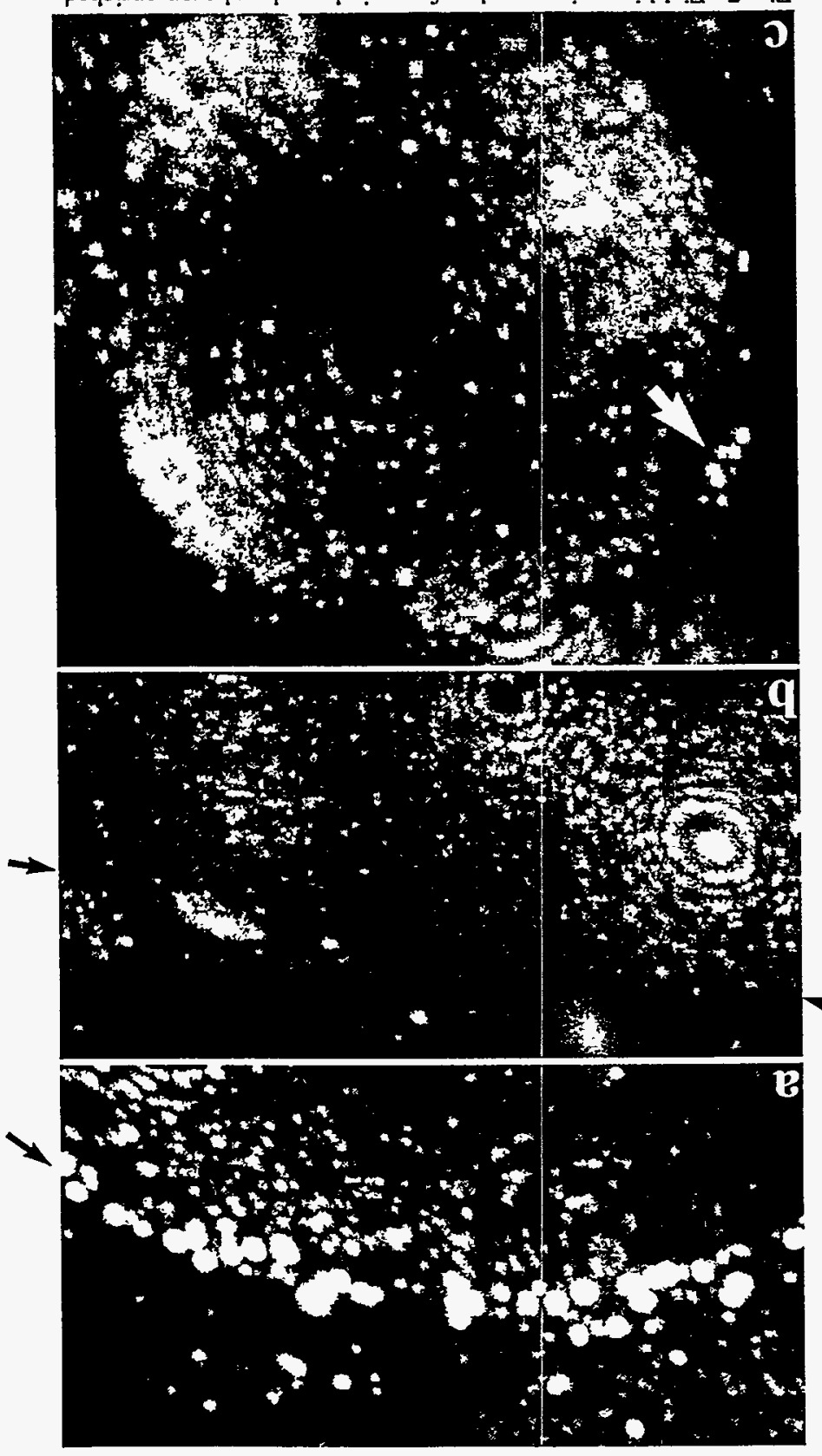

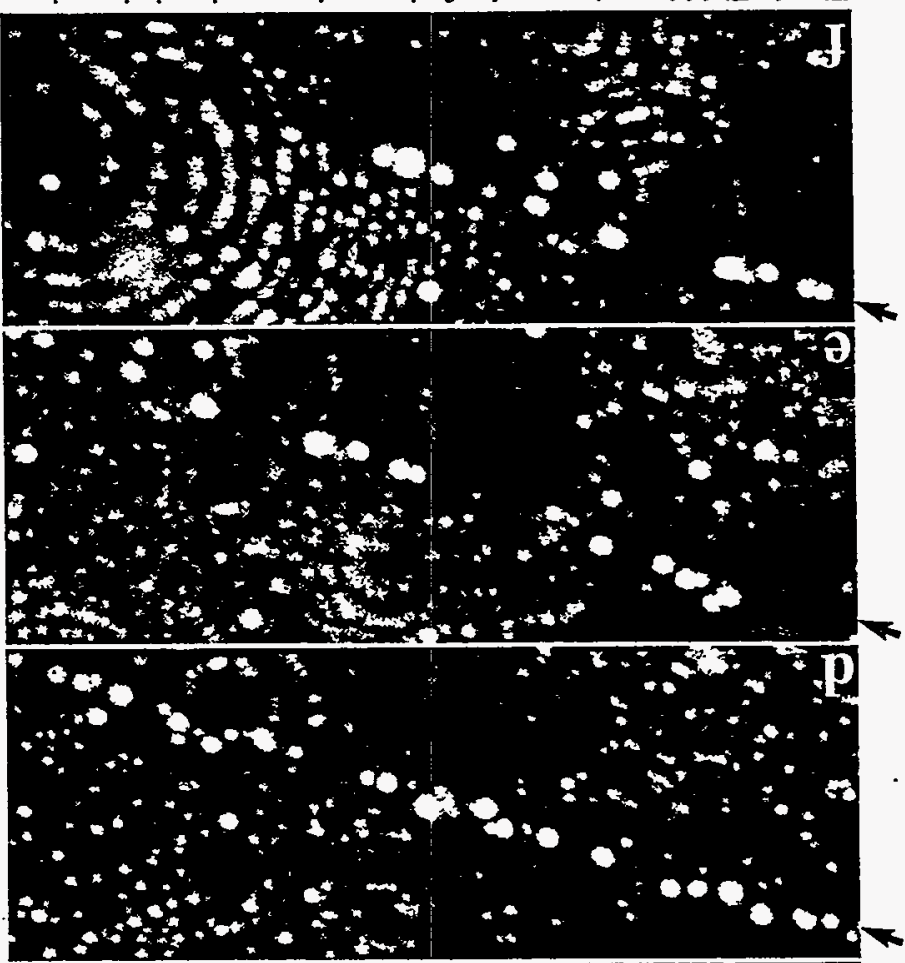
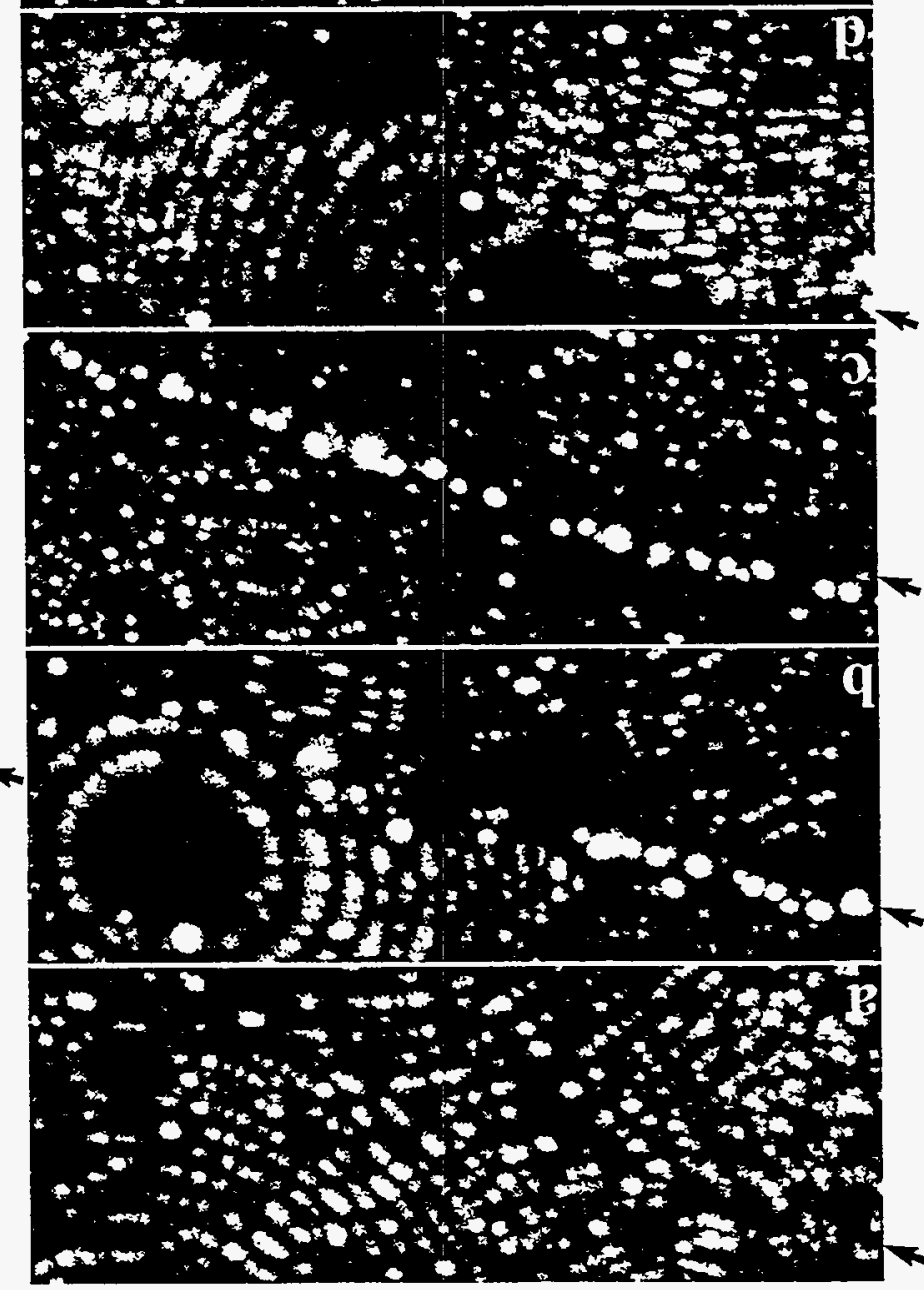
the field ion images of these boron-enriched regions does not necesarily indicate that they are amorphous regions since the imaging behavior of boride phases (see below) is such that few if any rings are normally observed in the field ion images of crystalline boride precipitates.

No ultrafine intragranular precipitates have been observed in these boron-doped Ni-24.2 at. \% Al alloys. However, boron clustering has been observed in alloys with higher aluminum contents ( $\mathrm{Ni}-25$ at. \% $\mathrm{Al}$ and $\mathrm{Ni}-26$ at. \% Al), as shown in Fig. 8 [18]. These features were found to contain up to approximately 10 boron atoms and were classified as clusters due to their small size and the absence of any other elements. The presence of these clusters suggests that there is a abrupt change in the boron matrix solubility at the stoichiometric composition.

\section{NiAI}

In boron-doped $\mathrm{NiAl}$, atom probe analyses revealed that boron segregates to the grain boundaries, as shown in Fig. 9. As in the case of $\mathrm{Ni}_{3} \mathrm{Al}$, the variation of the brightly-imaging boron atoms indicated that the boron coverage varied along the grain boundary. Due to the favorable orientation of this grain boundary, $\phi=90^{\circ}$, several analyses at different positions along its length were possible. The results are summarized in Table 2 in order of analysis position along the boundary. The boron coverage was found to vary by a factor of -7.5 from 3.6 to $27.4 \%$ or $\Gamma_{i}=6.2$ to $46.3 \times 10^{17}$ atoms $\mathrm{m}^{-2}$. Most sections of the boundary exhibited nickel depletion ( $\mathrm{Ni}: \mathrm{Al}=0.84)$ with one section exhibited a significant nickel enrichment ( $\mathrm{Ni}: \mathrm{Al}=1.27)$. Boron enrichment was observed in both nickel depleted and nickel enriched sections. No strong correlation between the $\mathrm{Ni}: \mathrm{Al}$ ratio and the coverage was apparent in these data. It should be noted that despite the extremely small radius of the cylinder of analysis used in these grain boundary analyses, $r_{a}=0.4$ to $r_{a}=0.75 \mathrm{~nm}$, a significant number of atoms from the grain interior on either side of the boundary were also collected. Although this extended radius does not affect the coverage, it influences the accuracy of the $\mathrm{Ni}$ :Al ratio at the exact boundary plane.

Table 2. The Gibbs interfacial excesses of boron at a $\Sigma 3$ coincident site lattice grain boundary in $\mathrm{NiAl}+0.04$ at. \% B aged $1 \mathrm{~h}$ at $900^{\circ} \mathrm{C}$.

\begin{tabular}{|c|c|c|c|}
\hline Analysis & $\begin{array}{c}\text { Ni:Al } \\
\text { Ratio }\end{array}$ & $\begin{array}{c}\text { Gibbs Interfacial } \\
\text { Excess } \Gamma \text {. atoms } \mathrm{m}^{2}\end{array}$ & $\begin{array}{c}\text { Coverage } \\
\%\end{array}$ \\
\hline 1 & 0.77 & $9.6 \times 10^{17}$ & 5.7 \\
2 & 0.91 & $6.2 \times 10^{17}$ & 3.6 \\
3 & 1.27 & $8.7 \times 10^{17}$ & 5.2 \\
4 & 0.79 & $8.7 \times 10^{17}$ & 5.2 \\
5 & 0.80 & $1.2 \times 10^{18}$ & 7.2 \\
6 & 0.88 & $1.3 \times 10^{18}$ & 7.6 \\
7 & 0.84 & $2,3 \times 10^{18}$ & 13.4 \\
8 & 0.94 & $1.5 \times 10^{18}$ & 9.1 \\
9 & 0.82 & $1.9 \times 10^{18}$ & 11.0 \\
10 & 0.81 & $4,6 \times 10^{18}$ & 27.4 \\
Average & 0.88 & $1.6 \times 10^{18}$ & 9.5 \\
\hline
\end{tabular}

Previous atom probe characterization of a binary $\mathrm{Ni}-49$ at. \% $\mathrm{Al}$ alloy by Camus et al. demonstrated that approximately two thirds of the analyzed grain boundaries were depleted in aluminum to $-40 \pm 1 \% \mathrm{Al}$ ( $\mathrm{Ni}: \mathrm{Al}=1.5$ ) at the boundary and the remaining one third did not exhibit any significant depletion $[24,25]$.

Unlike boron-doped $\mathrm{Ni}_{3} \mathrm{Al}$ which exhibits significant matrix boron solubility, atom probe analysis of the matrix in an $\mathrm{NiAl}+0.15$ at. \% B alloy revealed that the boron solubility was extremely low $(0.003 \pm 0.007$ at. \% B after aging for $1 \mathrm{~h}$ at $500^{\circ} \mathrm{C}$ and $0.026 \pm 0.003$ at. \% B after aging for $1 \mathrm{~h}$ at $1100^{\circ} \mathrm{C}$ ) [22]. However, the boron in the matrix and at the grain boundaries does not fully account for the total boron in the material and indicates that the remaining boron must be associated with another microstructural feature.
The majority of the boron was determined to be partitioned to ultrafine precipitates ranging in size from 1 to $20 \mathrm{~nm}$, as shown in Fig. 10. Atom probe analysis revealed that the precipitate composition was consistent with a $\mathrm{MB}_{2}$ type precipitate where the metallic content $M$ was a mixture of titanium, vanadium, chromium and tungsten. The metallic content was found to vary significantly from precipitate to precipitate suggesting that these precipitates were formed from the trace elements in the material. Some carbon was also detected in these precipitates. Similar ultrafine MC precipitates have also been observed in carbon-doped NiAl [22] and un-doped single crystal NiAl [23].

Due to their smail size and relatively high number density, these precipitates produce significant precipitation hardening and are therefore detrimental to the mechanical properties. This precipitation hardening also offsets the benefits of the boron segregation to the high angle grain boundaries. It has been shown that the number density of these precipitates can be decreased by reducing the quantities of trace impurities in the alloy by zone refinement [23]. Alternatively, the number density of these precipitates can be reduced and their size increased with an appropriate heat treatment [22].

In NiAl containing 0.7 at. $\%$ Mo annealed $1 \mathrm{~h}$ at $1000^{\circ} \mathrm{C}$ and $\mathrm{l} h$ at $500^{\circ} \mathrm{C}$, atom probe analysis [26] indicated extremely low solubilities of the molybdenum and other trace impurities in the matrix: $\mathrm{Ni}-50.4 \pm 1.2$ at. \% Al $-0.005 \pm 0.001 \% \mathrm{Mo}, 0.007 \pm 0.002 \% \mathrm{Fe}, 0.005 \pm 0.001 \% \mathrm{Si}$ and $N$ and $0.0004 \pm 0.0004 \% \mathrm{~V}$. The large error on the aluminum content indicates a significant variation from one region to another.

The majority of the molybdenum in this alloy was found to be concentrated in a low number density $\left(-1\right.$ to $\left.2 \times 10^{21} \mathrm{~m}^{-3}\right)$ of 10 - to 50 nm-diameter spherical molybdenum precipitates. The composition of these body-centered cubic precipitates was determined to be Mo- $3.3 \pm$ 0.6 at. \% Al with residual amounts of $0.06 \pm 0.03 \% \mathrm{~B}, 0.04 \pm 0.02 \% \mathrm{Ni}$, $0.01 \pm 0.01 \% \mathrm{Fe}$, and $0.04 \pm 0.02 \% \mathrm{~V}$. The precipitates were observed both in the NiAl matrix, as shown in Fig. 11, and also at grain boundaries. Calculations based on an Orowan mechanism indicate that these precipitates generate a significant increase in yield stress of between 82 and $210 \mathrm{MPa}$ depending on the measured minimum and maximum size of the precipitate. These values are in good agreement with the differences in the yield stresses of the molybdenum-doped (254 $\mathrm{MPa}$ ) and undoped alloys (154 $\mathrm{MPa}$ ) since a larger number of the smaller diameter precipitates were observed.

A field ion micrograph of a $\Sigma 3$ coincident site lattice grain boundary in NiAl containing 0.7 at. \% Mo annealed $1 \mathrm{~h}$ at $1000^{\circ} \mathrm{C}$ and $1 \mathrm{~h}$ at $500^{\circ} \mathrm{C}$ is shown in Fig. 12. Due to the favorable orientation of the grain boundary plane with respect to the specimen axis, $\phi=90^{\circ}$. extensive characterization of this boundary was possible. The Gibbsian interfacial excesses of the solutes along this boundary are summarized in Table 3. These coverages were significantly lower than the boron coverages observed in the boron-doped NiAl. Despite the relatively low coverages, significant enrichments of molybdenum, nitrogen and silicon, carbon, boron, and iron are evident at the grain boundary.

Table 3. The Gibbs interfacial excesses of solute at a $\Sigma 3$ coincident site lattice grain boundary in $\mathrm{NiAl}+0.7$ at. \% Mo aged $1 \mathrm{~h}$ at $1000^{\circ} \mathrm{C}$ and $1 \mathrm{~h}$ at $500^{\circ} \mathrm{C}$.

\begin{tabular}{|c|c|c|}
\hline Element & $\begin{array}{c}\text { Gibbs Interfacial Excess, } \Gamma_{\mathbf{i}} \\
\text { atoms } \mathrm{m}^{-2}\end{array}$ & $\begin{array}{c}\text { Coverage } \\
\%\end{array}$ \\
\hline $\mathrm{Mo}$ & $9.9 \times 10^{16}$ & 0.58 \\
$\mathrm{~N} / \mathrm{Si}$ & $6.5 \times 10^{16}$ & 0.38 \\
$\mathrm{C}$ & $1.1 \times 10^{16}$ & 0.07 \\
$\mathrm{~B}$ & $5.7 \times 10^{15}$ & 0.03 \\
$\mathrm{Fe}$ & $3.8 \times 10^{15}$ & 0.02 \\
\hline
\end{tabular}

A $2 \mathrm{l} / 2 \mathrm{D}$ reconstruction of the solute distribution along this grain boundary is shown in Fig. 13. This reconstruction was created by taking the $z$ coordinate of each solute atom as position along the composition profile. The solutes were then assumed to be randomly distributed along the grain boundary plane to give the $x$ coordinate $(y=0)$. Since the diameter of the cylinder of analysis varied from 3.4 to $4.3 \mathrm{~nm}$ during this 

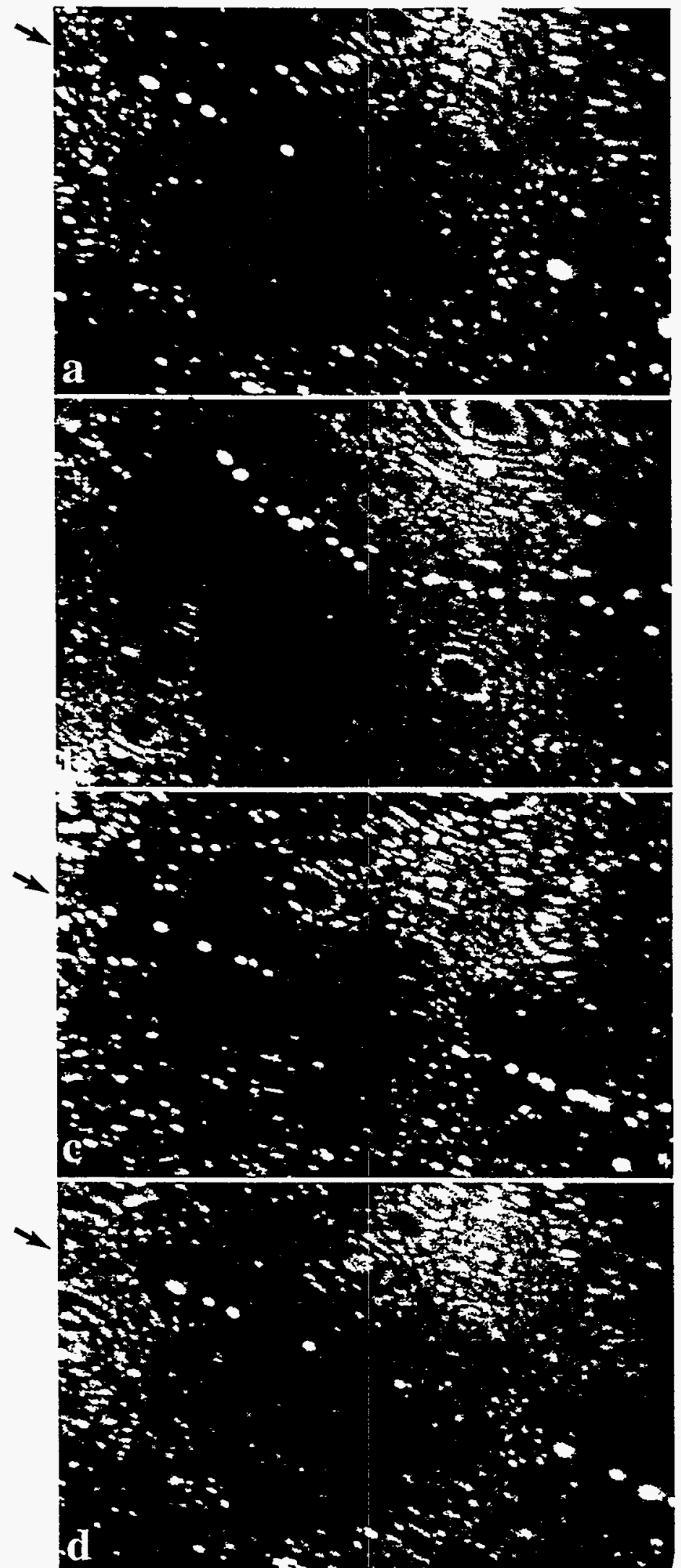

Fig. 9. Field ion micrographs of a boron-decorated grain boundary in NiAl.

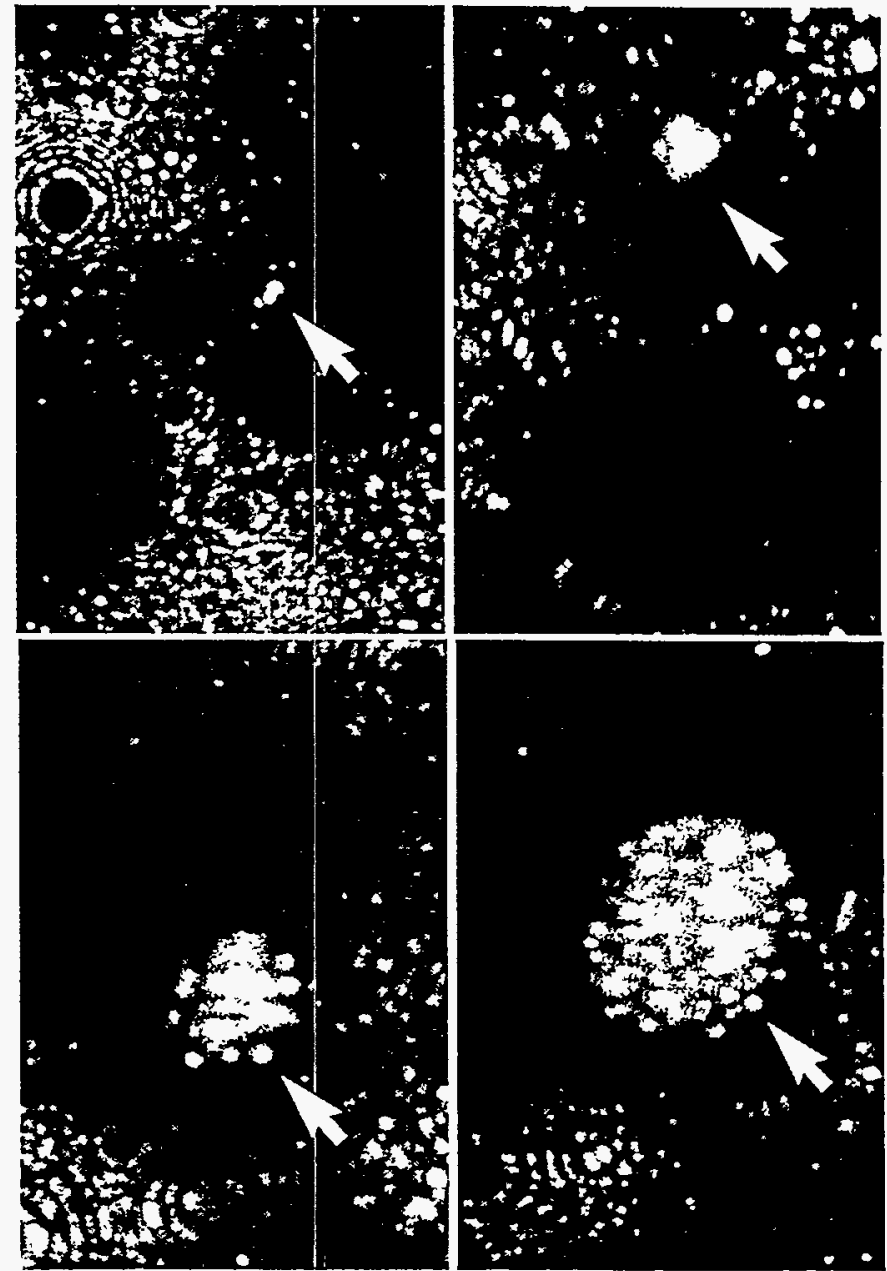

Fig. 10. Field ion micrographs of $\mathrm{MB}_{2}$-type precipitates in NiAl.

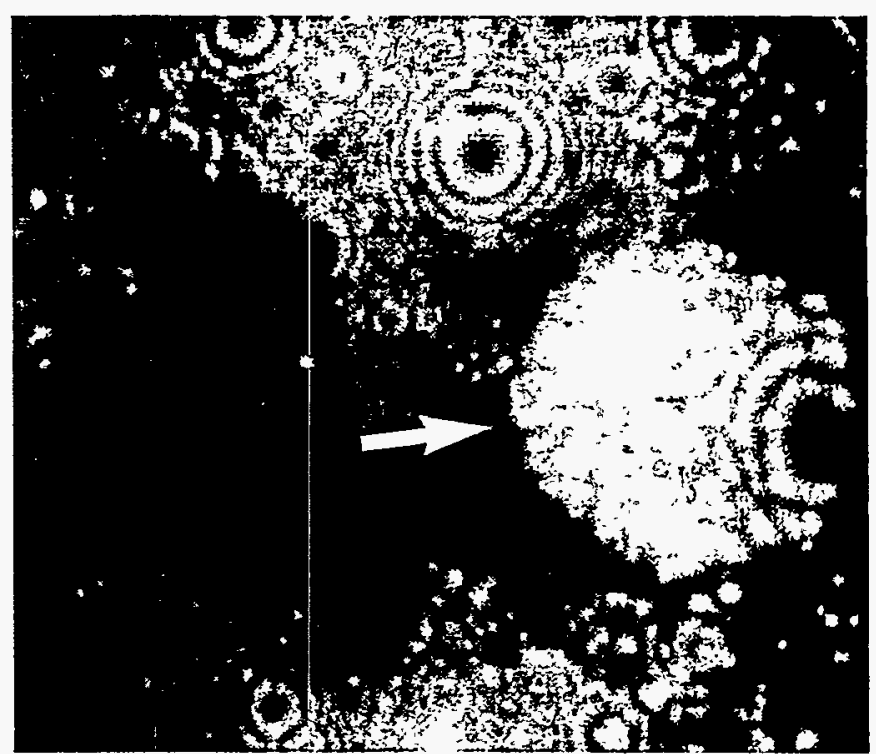

Fig. 11. Field ion micrograph of a molybdenum precipitate in molybdenum-doped $\mathrm{NiAl}$. 
analysis, this randomization will only introduce a small one-dimensional uncertainty in the reconstruction. Although most of the solute was distributed uniformly along the grain boundary, there was some visual evidence of regions of higher than average local concentrations of iron, molybdenum, nitrogen and carbon. There was also some evidence of molybdenum-nitrogen enrichment. This small non-uniformity in the solute distribution may arise from small changes in the boundary plane or the presence of grain boundary dislocations which changes the local atomic environment and thereby influence the segregation behavior.

\section{TiAl}

These materials differ from the previous examples in that they contain two primary phases: an $\mathrm{Ll}_{0}$-ordered $\gamma$ phase and a $\mathrm{DO}_{14}$-ordered $\alpha_{2}$ phase. In addition, the compositions of these phases vary significantly depending on the heat treatment and may be far from their equilibrium or steady state values. For example, in the materials examined, the aluminum content of the $\gamma$ phase was found to vary from $-40-50$ at. \% Al and that of the $\alpha_{2}$ phase was typically $34-36$ at. \% Al. Due to these variations, the identity of phase based solely on the aluminum content alone was not reliable. Since the $\alpha_{2}$ phase is known to scavenge oxygen and other interstitial elements $[27,28]$, it typically has an oxygen content of one to two orders of magnitude higher than the $\gamma$ phase. For example, the oxygen content of the $\alpha_{2}$ phase in a Ti-47\% Al-2\% Cr-1.8\% Nb$0.2 \% \mathrm{~W}-0.15 \% \mathrm{~B}$ alloy was found to be -33 times that of the $\gamma$ phase. Therefore, phase identification was based on the measured aluminum content in conjunction with the measured oxygen levels as well as the appearance of the phase in the field ion image.

Field ion micrographs of the $\gamma$ and brightly-imaging $\alpha_{2}$ phases are shown in Fig. 14. The width of these $\alpha_{2}$ laths was found to vary from less than $5 \mathrm{~nm}$ (Fig. 14b) to more than $20 \mathrm{~nm}$ (Fig. 14a) in Ti-47\% Al-2\% Cr$1.8 \% \mathrm{Nb}-0.2 \% \mathrm{~W}-0.15 \% \mathrm{~B}$ that was stress-relieved for $2 \mathrm{~h}$ at $900^{\circ} \mathrm{C}$. No evidence for boron segregation to the $\gamma-\alpha_{2}$ phase interface has been obtained from atom probe analysis of the interface.

These materials also contain a significant number of $\gamma-\gamma$ interfaces as shown in Fig. 15. However, no evidence for boron segregation to the $\gamma-\gamma$ phase interface has been obtained. The segregation behavior of the other microalloying elements is discussed below.

The boron levels in the $\gamma$ and $\alpha_{2}$ phases were found to be significantly depleted from the bulk alloy concentration. For example, the solubilities of boron in the $\gamma$ and $\alpha_{2}$ matrix phases were found to be $0.011 \pm 0.006$ at. $\% \mathrm{~B}$ and $<0.003$ at. \% $\mathrm{B}$, respectively in $\mathrm{Ti}-47 \% \mathrm{Al}-2 \% \mathrm{Cr}-1.8 \% \mathrm{Nb}-$ $0.2 \% \mathrm{~W}-0.15 \% \mathrm{~B}$ that was stress-relieved for $2 \mathrm{~h}$ at $900^{\circ} \mathrm{C}$.

The majority of the boron was concentrated in a variety of borides including $\mathrm{TiB}, \mathrm{TiB}_{2}$ and a chromium-enriched $(\mathrm{Ti}, \mathrm{Cr})_{2} \mathrm{~B}$ precipitate [29]. A field ion micrograph of a $\mathrm{M}_{2} B$ precipitate in a $\mathrm{Ti}-47 \% \mathrm{Al}-2 \% \mathrm{Cr}$ $1.8 \% \mathrm{Nb}-0.2 \% \mathrm{~W}-0.15 \% \mathrm{~B}$ alloy that was stress-relieved for $2 \mathrm{~h}$ at $900^{\circ} \mathrm{C}$ is shown in Fig. 16. With the exception of the smaller $(<50 \mathrm{~nm}$ thick) chromium-enriched $(\mathrm{Ti}, \mathrm{Cr})_{2} \mathrm{~B}$ precipitates, most of the borides were larger than the field of view of the field ion microscope, i.e., greater than $-100 \mathrm{~nm}$. The compositions of some of the precipitates are summarized in Table 4. It is evident that a significant proportion of the microalloying additions is present in these boride precipitates. The partitioning of the microalloying elements to these borides may reduce their availability for other more beneficial mechanisms. Although these coarse borides may help pin the grain boundaries and retard grain growth, it is likely that improvements could be made in the effectiveness of the boron additions.

Table 4. Composition of boride precipitates as measured in the atom probe. (atomic \%)

\begin{tabular}{|c|c|c|}
\hline Alloy & Mensured Composition & Type \\
\hline $\begin{array}{l}\text { Ti-47\% Al-2\% Cr- } \\
1.8 \% \text { Nb-0.2\% W- } \\
0.15 \% \text { B }\end{array}$ & 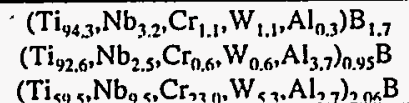 & $\begin{array}{l}\mathrm{MB}_{2} \\
\mathrm{MB}^{2} \\
\mathrm{M}_{2} \mathrm{~B}\end{array}$ \\
\hline
\end{tabular}

A field ion micrograph of an $\alpha_{2}-\gamma$ interface in a tungsten containing Ti$47 \% \mathrm{Al}-2 \% \mathrm{Cr}-1.8 \% \mathrm{Nb}-0.2 \% \mathrm{~W}-0.15 \% \mathrm{~B}$ alloy that was stressrelieved for $2 \mathrm{~h}$ at $900^{\circ} \mathrm{C}$ is shown in Fig. 17. Several brightly-imaging atoms are apparent both at the interface and in the near boundary region in the $\alpha_{2}$ phase. Since this alloy contains boron and several refractory elements that all exhibit similar brightly-imaging behavior, it is not possible to positively identify these brightly-imaging atoms from their appearance in the field ion image. The average tungsten content of the $\gamma$ phase in this material was determined to be $0.16 \pm 0.02$ at. \% W. The tungsten content of the $\alpha_{2}$ phase was found to vary significantly from one region to another [30]. The measured compositions ranged from $0.17 \pm 0.15$ at. \% W to $0.39 \pm 0.08$ at. \% W with an average of $0.33 \pm$ 0.06 at. \% W. Part of this variation may be due to a tail in the segregation profile at the $\alpha_{2}-\gamma$ interface as indicated by the width of the decoration in the field ion micrograph. These results indicate that tunsgten is partitioning to the $\alpha_{2}$ phase. The $\alpha_{2}-\gamma$ interface region was found to be enriched to a level of $0.68 \pm 0.45$ at. \% W. The tungsten interfacial segregation supports the previous observation that tungsten additions stabilize the $\alpha_{2}$ lamellae against dissolution during thermal aging [8-10].

Tungsten segregation to the $\gamma-\gamma$ interfaces was also observed in these materials [30]. A composition profile taken such that the axis of the cylinder of analysis was aligned almost precisely along a $\gamma-\gamma$ interface is shown in Fig. 18. The orientation of the interface with respect to the specimen axis is shown in the transmission electron micrograph of the needle-shaped field ion specimen shown in Fig. 19. This orientation permitted the distribution of solute along the interface to be examined. It is evident from the composition profile that there was a significant and relatively uniform enrichment of tungsten at this $\gamma-\gamma$ interface. The average coverage at this interface was determined to be $4.6 \% \mathrm{~W}$ (Gibbsian interfacial excess $\Gamma_{1}=6.4 \times 10^{17} \mathrm{~m}^{-2}$ ). This coverage gives an enhancement factor of -29 over the $\gamma$ matrix level. A tungsten composition profile taken across a $\gamma-\gamma$ interphase is shown in Fig. 20a. The average coverage at this interface was determined to be $3.7 \% \mathrm{~W}$ (Gibbsian interfacial excess $\Gamma_{1}=4.7 \times 10^{17} \mathrm{~m}^{-2}$ ). This coverage gives an enhancement factor of -23 over the $\gamma$ matrix level. The chromium and niobium composition profiles taken across this $\gamma-\gamma$ interphase are also shown in Fig. 20b. Although the chromium indicates some enrichment at this $\gamma-\gamma$ interface, the niobium does not. The variation in chromium enrichment from interface to interface is in agreement with previous results from Yamaguchi et al. [31, 32].

The chromium and niobium additions were also found to partition between the $\gamma$ and $\alpha_{2}$ phases. In Ti-47\% Al-2\% Cr-1.8\% Nb-0.2\% W $0.15 \% \mathrm{~B}$ that was stress-relieved for $2 \mathrm{~h}$ at $900^{\circ} \mathrm{C}$, the average chromium content of the $\alpha_{2}$ phase was $2.9 \pm 0.2$ at. \% $\mathrm{Cr}$ and that of the $\gamma$ phase was $1.6 \pm 0.06$ at. $\% \mathrm{Cr}$ indicating that chromium is enriched in the $\alpha_{2}$ phase. In the Ti-47\% Al-2\% Cr-1.8\% Nb-0.2\% W $-0.15 \%$ B alloy, the niobium was also found to have a slight preference for the $\gamma$ phase ( $1.9 \pm 0.06$ at. \% Nb) over the $\alpha_{2}$ phase $(1.6 \pm 0.13$ at. \% Nb).

Atom probe analyses of the chromium and niobium levels at both the $\gamma-\gamma$ and $\gamma-\alpha_{2}$ phase interfaces revealed that some interfaces were enriched in both niobium and chromium and some interfaces exhibited no enrichments.

\section{Conclusions}

In boron-doped $\mathrm{Ni}_{3} \mathrm{Al}$, the boron additions were found to segregate to dislocations, low angle boundaries, stacking faults, antiphase boundaries, and grain boundaries. The boron and aluminum levels at grain boundaries were found to vary both from boundary to boundary and also along an individual boundary segment. In some cases, a boron-enriched thin film up to $3 \mathrm{~nm}$ thick was observed. In aluminum-enriched $\mathrm{Ni}_{3} \mathrm{Al}$. ultrafine clusters containing up to approximately 10 boron atoms were detected in the matrix.

In contrast, the majority of the boron in boron-doped NiAl was determined to be in the form of ultrafine $\mathrm{MB}_{2}$-type precipitates. These precipitates are detrimental to the mechanical properties and offset the benefits of the boron segregation to the high angle grain boundaries. In molybdenum-doped $\mathrm{NiAl}$, atom probe analyses indicated extremely low 


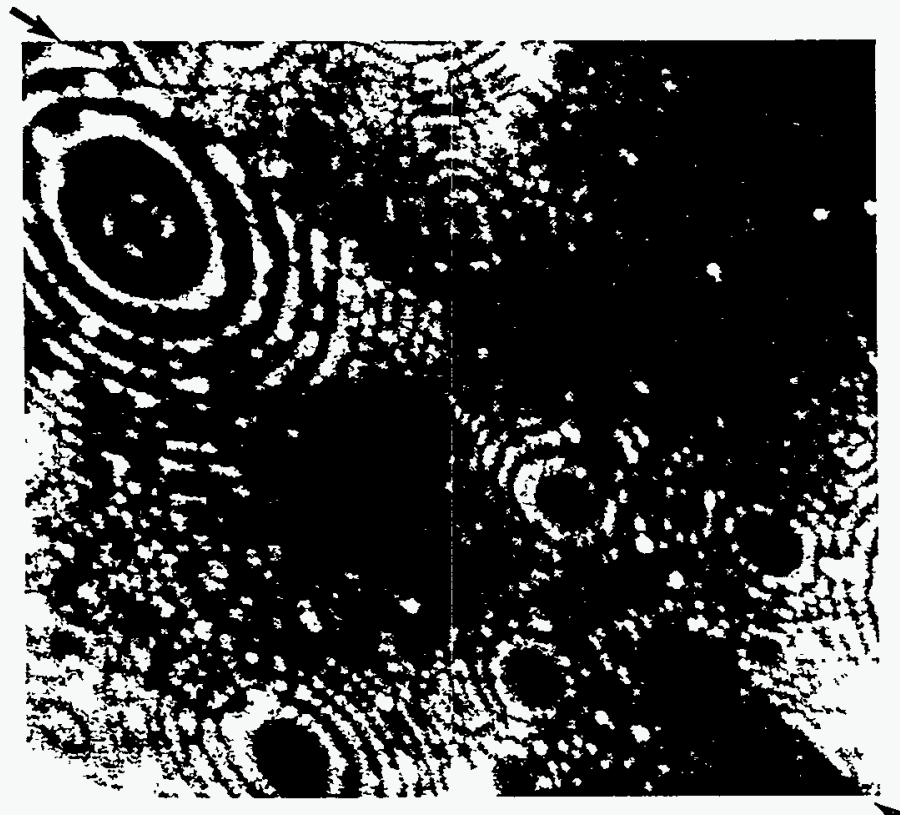

Fig. 12. Field ion micrograph of a $\Sigma 3$ grain boundary in molybdenum-doped $\mathrm{NiAl}$.

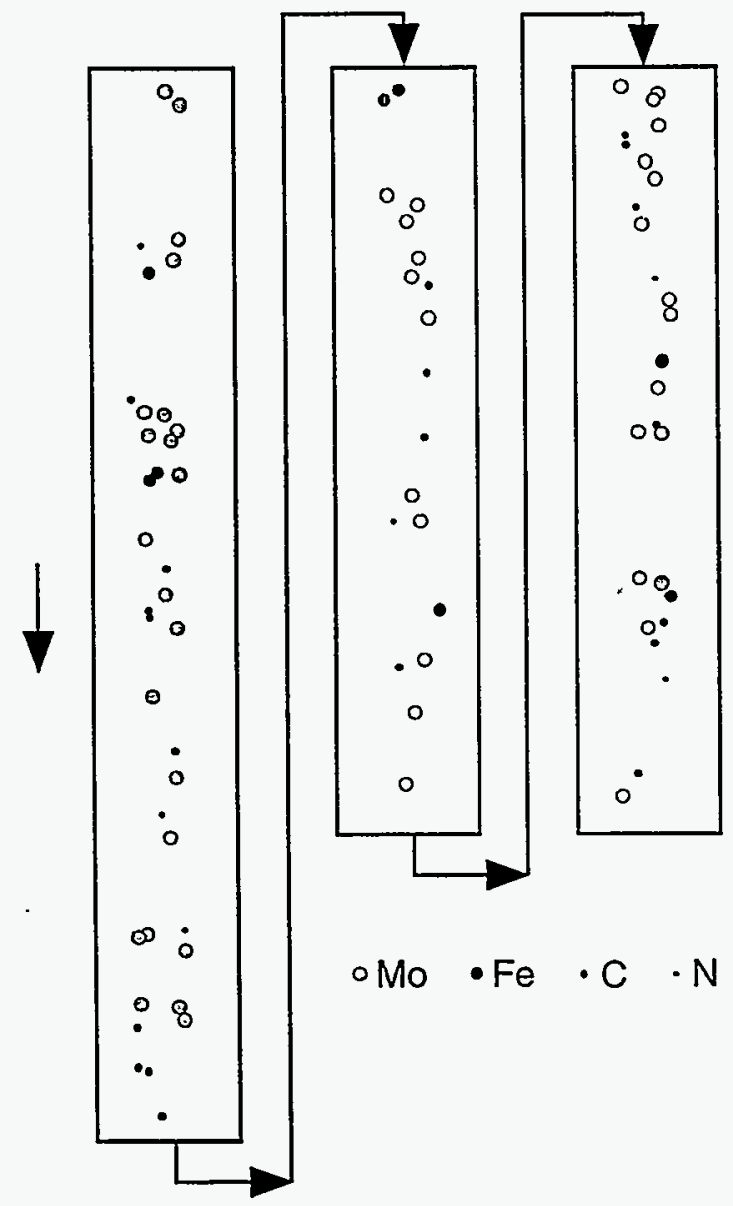

Fig. 13. Reconstruction of the solute segregation along a $\Sigma 3$ grain boundary in molybdenum-doped NiAl. Each symbol is an individual atom.

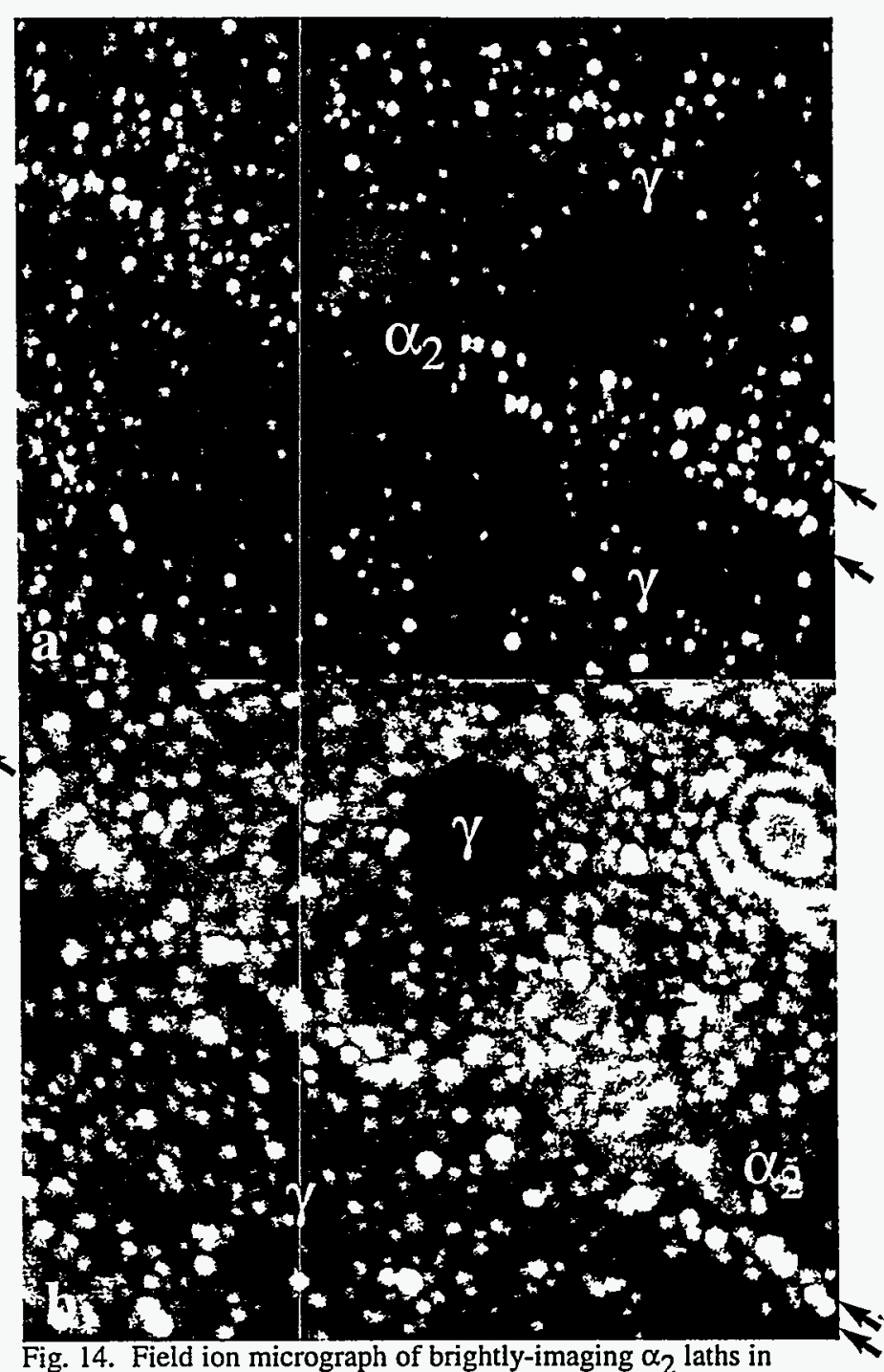

Fig. 14. Field ion micrograph of brightly-imaging $\alpha_{2}$ laths in TiAl. (a) $5 \mathrm{~nm}$ and (b) $20 \mathrm{~nm}$ thick.

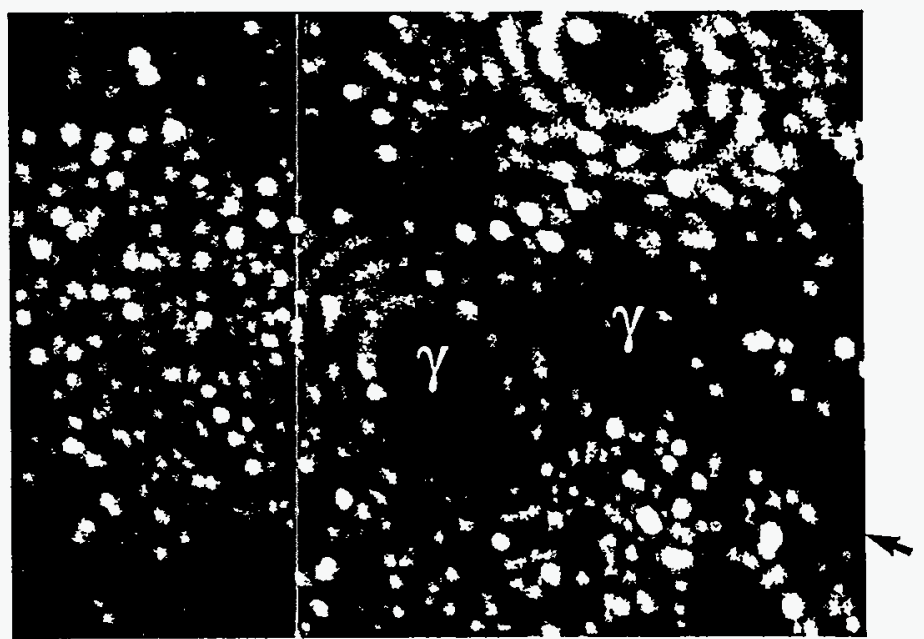

Fig. 15. Field ion micrograph of a $\gamma-\gamma$ interface in TiAl. 


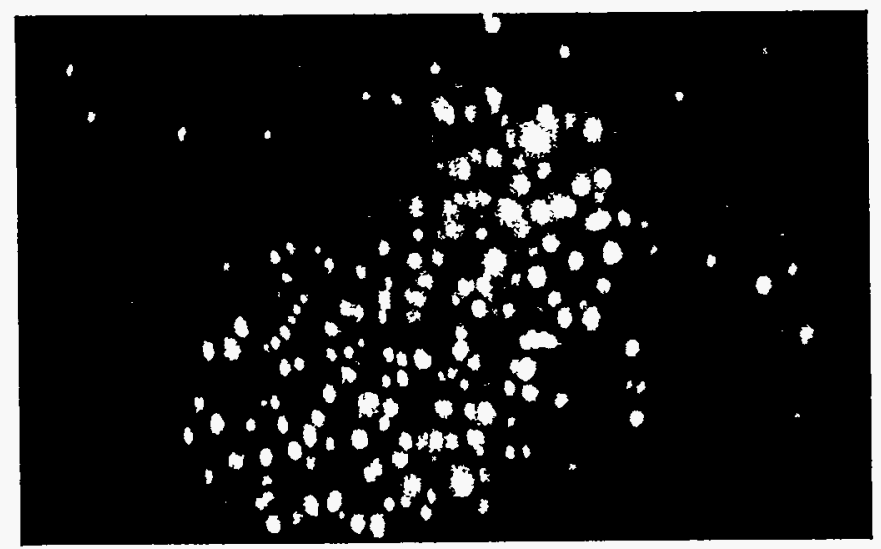

Fig. 16. Field ion micrograph of a chromium-enriched $\mathrm{M}_{2} \mathrm{~B}$ precipitate in TiAl.

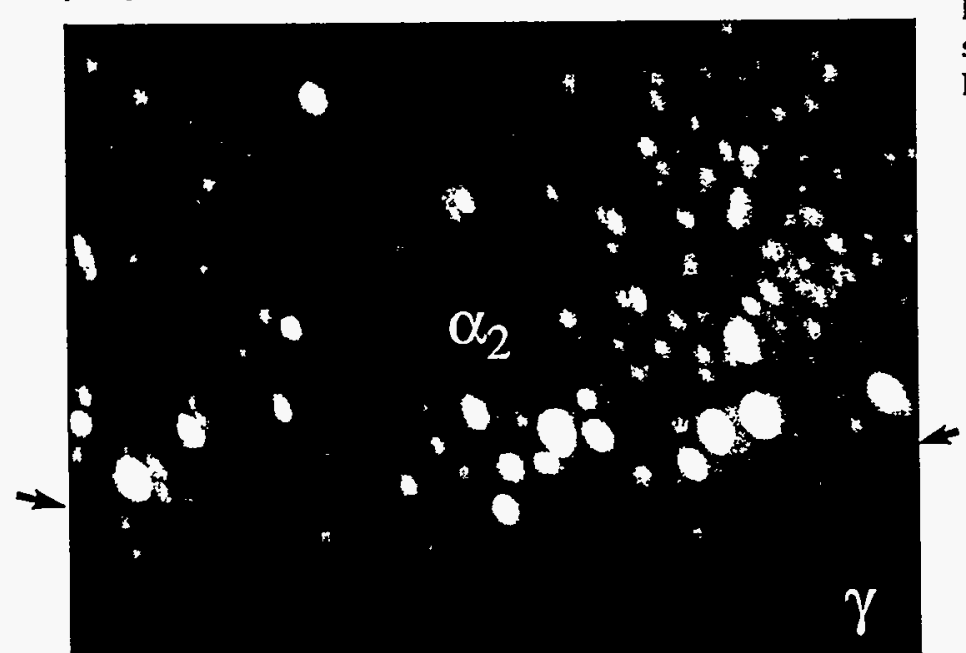

Fig. 17. Field ion micrograph of an $\alpha_{2}-\gamma$ interface in TiAl.

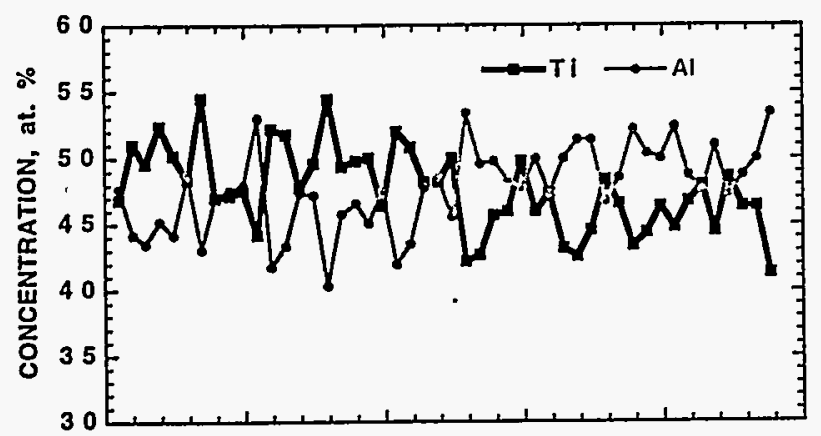

$$
\text { ஃे }
$$

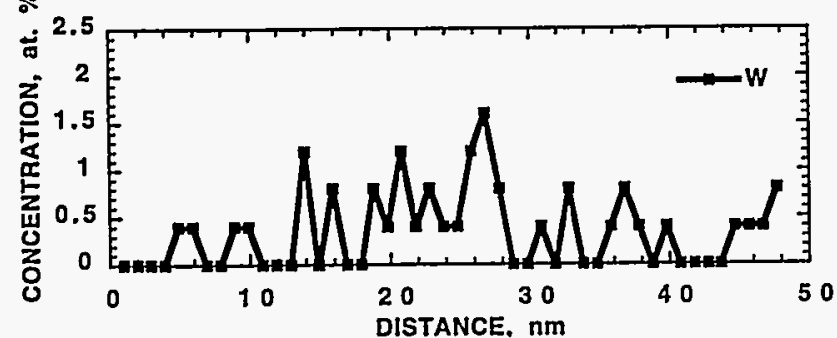

Fig. 18. Composition profile along a $\gamma-\gamma$ interface in TiAl.

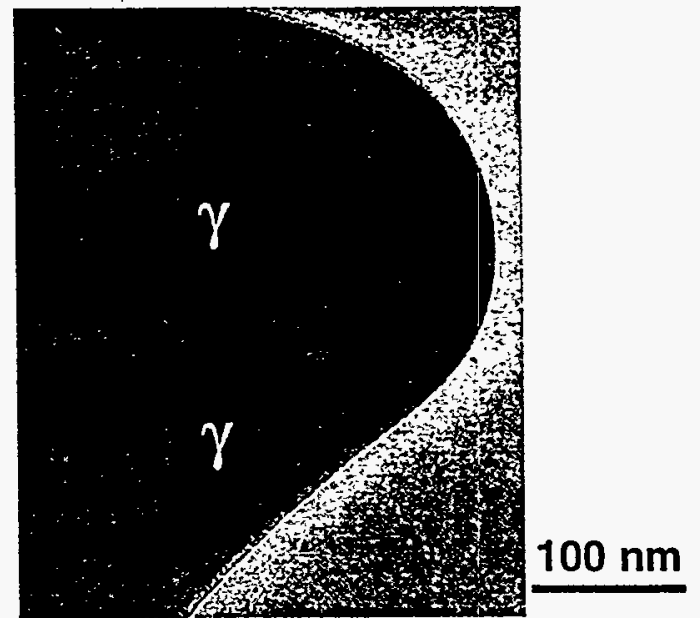

Fig. 19. Transmission electron micrograph of the field ion specimen used to produce the composition profile shown in Fig. 18
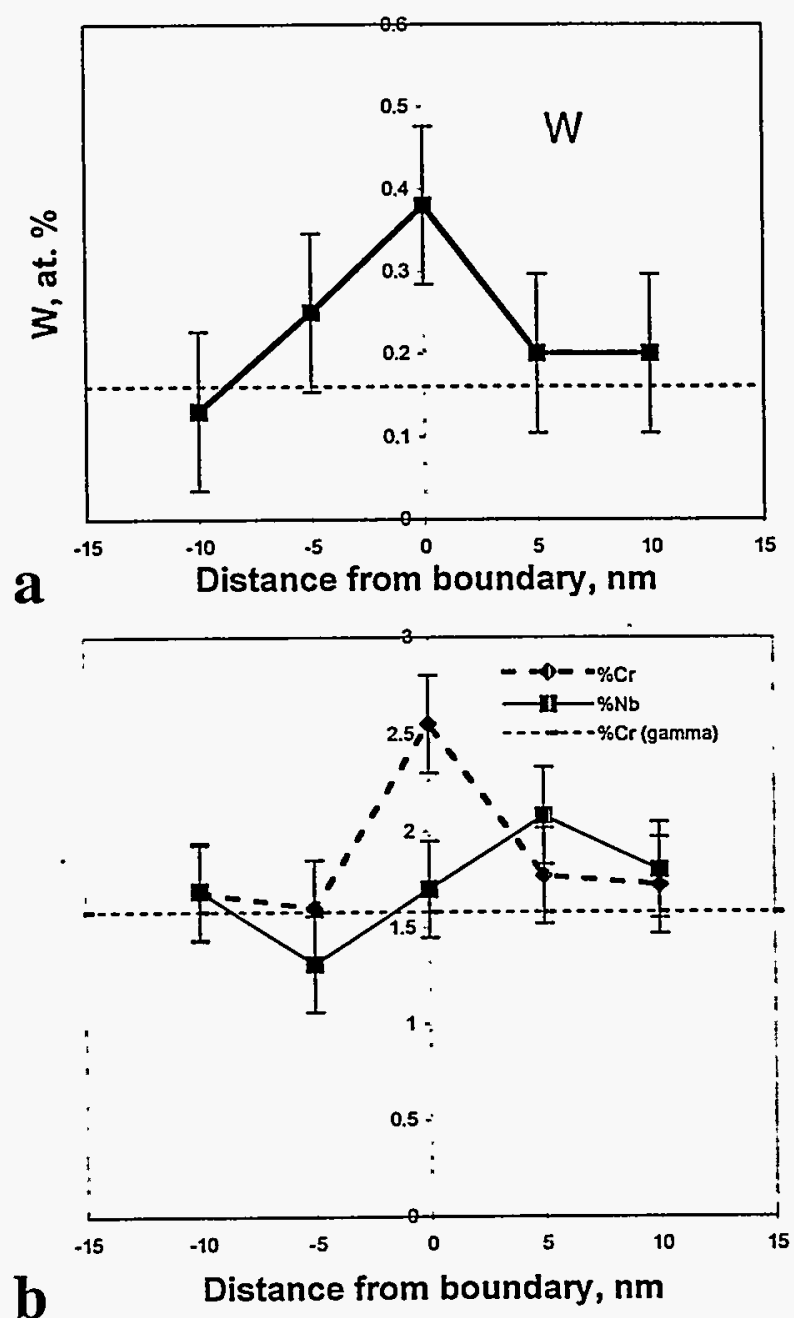

Fig. 20. Composition profiles for tungsten, chromium and niobium across a $\gamma-\gamma$ interface in TiAl. 
solubilities of the molybdenum and other trace impurities in the matrix and significant enrichments of molybdenum, nitrogen and silicon, boron, and iron at the grain boundaries.

In boron-doped two phase $\alpha_{2}+\gamma$ TiAl containing chromium, niobium, and tungsten, the boron level was found to be significantly depleted from the bulk level in both the $\alpha_{2}$ and $\gamma$ phases and a variety of coarse borides including $\mathrm{TiB}, \mathrm{TiB}_{2}$ and a finer chromium-enriched $(\mathrm{Ti} . \mathrm{Cr})_{2} \mathrm{~B}$ precipitate was observed. The tungsten and chromium were determined to partition preferentially to the $\alpha_{2}$ phase and also to segregate to the $\alpha_{2}-\gamma$ and $\gamma-\gamma$ interfaces. These results indicate that a significant proportion of the microalloying elements are consumed by the boride precipitates.

\section{Acknowledgments}

The authors would like to thank Drs. J. A Horton, C. T. Liu, I. M. Anderson. A. J. Duncan and R. Jayaram for their contributions to the results presented in this paper. This research was supported by the Division of Materials Sciences, U. S. Department of Energy under contract DE-AC05-960R22464 with Lockheed Martin Energy Research Corp. and through the SHaRE Program under contract DE-AC05760 R00033 with Oak Ridge Associated Universities.

\section{References}

I. K. Aoki and O. Izumi, Nippon Kinzoku Gakkaishi, 43 (1979) 1190.

2. C. T. Liu, C. L. White and J. A. Horton, "Effect of Boron on Grain Boundaries in $\mathrm{Ni}_{3} \mathrm{Al}$ ", Acta Metall, 33 (1985) 213-229.

3. R. D. Noebe, R.R. Bowman and M.V. Nathal, "Physical and Mechanical Properties of the B2 compound NiAl". Inter. Mater Rev, 38 (1993) 193-232.

4. C.T. Liu and J.A. Horton, "Effect of refractory alloying additions on mechanical properties of near-stoichiometric NiAl", Mater. Sci. Eng. A, 192/193 (1995) 170-178.

5. S. C Huang, "Alloying Considerations in Gamma-Based Alloys" Structural Intermetallics, eds. R. Darolia, J. Lewandowski, C. T. Liu, P. Martin, D. Miracle and M. Nathal, TMS. Warrendale, PA. 1993, p. 299-308.

6. S.C. Huang and E.L. Hall, "Structure and Properties of TiAl Alloys Containing Interstitial Elements", Proc. High Temperature Ordered Intermetallic Alloys IV, Boston, December 1990), vol. 213, L. Johnson, D.P Pope and J.A. Horton, (eds.) (Pittsburgh, PA, Materials Research Society, 1991), pp.827832

7. T. Nakano, and Y. Umakoshi, "Effect of Boron Addition on the Plastic Behavior of PST Crystals in TiAl", Intermetallics. 2 (1994) 185-191.

8. R. V. Ramanujan, P. J. Maziasz, and C. T. Liu. "The Thermal Stability of the Microstructure of Gamma-Based Titanium Aluminides", Acta. Metal!, 44 (1996) 2611-2642.

9. C. T. Liu, J. H. Schneibel, P. J. Maziasz, J. L.Wright and D.S Easton, "Tensile Properties and Fracture Toughness of TiAl Alloys with Controlled Microstructures", Intermetallics, 4 (1996) 429-440.

10. P. J. Maziasz, R. V. Ramanujan, C. T. Liu and J. L. Wright, "Effects of Boron and Tungsten Alloying Additions of the Formation and Stability of Lamellar Structures in Two-Phase Gamma-TiAl", Intermetallics, 5 (1997) 83-95.

11. Y.-W. Kim, "Ordered Intermetallic Alloys, Part III: Gamma Titanium Aluminides", $\mathrm{IOM}, 46$ (1994) 30-40.

12. M. K. Miller and G. D. W. Smith, Atom Probe Microanalysis: Principles and Applications to Materials Problems (Pittsburgh, PA, Material Research Society, 1989).

13. M.K. Miller, A. Cerezo, M.G. Hetherington and G. D. W. Smith, Atom Probe Field Ion Microscopy (Oxford, England, Oxford University Press. 1996).
14. M. K. Miller, "The ORNL Atom Probe", J de Physique, 47-C2 (1986) 493-498.

15. J. W. Gibbs, The Collected Works of J. Willard Gibbs, vol. I, (New Haven, CT, Yale University Press, 1948).

15. M. K. Miller and G. D. W. Smith, "Atom Probe Analysis of Interfacial Segregation", Appl.Surf, Sci., $87 / 88$ (1995) 243 -250 and references therein.

16. D. McLean, Grain Boundaries in Metals (London, England. Oxford University Press, 1957) 116

17. E.D. Hondros and M.P Seah, "Segregation to Interfaces", Inter, Mater. Rev., 22 (1977) 262-301.

18. M.K. Miller and J. A. Horton, "An Atom Probe Field Ion Microscope Study of Boron Decorated Grain Boundaries in $\mathrm{Ni}_{3} \mathrm{Al}^{\prime}$, Scripta Metall., 20 (1986) 789-792.

19. J. A. Horton and M. K. Miller, "Atom Probe Analysis of Grain Boundaries in Rapidly-solidified $\mathrm{Ni}_{3} \mathrm{Al}$ ", Acta Metall., 35 (1987) 133-141.

20. J. A. Horton and M. K. Miller, "An Atom Probe Study of Boron Segregation to Line and Planar Defects in $\mathrm{Ni}_{3} \mathrm{Al}$ ", Proc. High Temperature Ordered Intermetallic Alloys II, Boston, December 1987), vol. 81, N. S. Stoloff, C. C. Koch, C. T. Liu and O. Izumi, (eds.) (Pittsburgh, PA, Materials Research Society, 1987), pp. 105-110.

2I. M. K. Miller and J. A. Horton, "Direct Observation of Boron Segregation to Line and Planar Defects in $\mathrm{Ni}_{3} \mathrm{All}^{\prime}$, Le de Phusique, 48-C6 (1987) 379-384.

22. R. Jayaram and M.K. Miller, "An Atom Probe Study of Grain Boundary and Matrix Chemistry in Microalloyed NiAl", Acta Metall., 42 (1994) 1561-1572.

23. A. Duncan, M. J. Kaufman and M. K. Miller, "Segregation aof Interstitial Impurities in Single-crystal NiAi", Surf. Sci., 76/77 (1994) 160-164.

24. P.P. Camus, I. Baker, J.A. Horton and M.K. Miller, Grain Boundary Chemistry in NiAl, J, de Physiques, 49-C6 (1988) 329333.

25. M.K. Miller, R. Jayaram and P.P. Camus, "Grain Boundary Composition in NiAl", Scripta Metall, 26 (1992) 679-684.

26. M. K. Miller, I. M. Anderson and K. F. Russell, "Precipitation and Grain Boundary Segregation in Molybdenum-doped NiAl", Appl. Surf Sci., 94/95 (1996) 288-294.

27. R. Uemori, T. Hanamura and H. Morikawa, "Oxygen Scavenging Effect of the $\alpha$, Phase in the TiAl Intermetallic Compound", Scripta Metall., 26 (1992) 969-974.

28. A. Menand, S. Huget and A. Nerac-Pertaix, "Interstitial Solubility in $\gamma$ and $\alpha_{2}$ Phases of TiAl-Based Alloys", Acta. Mater. 44 (1996) 4729-4737.

29. D.J. Larson, C. T. Liu and M. K. Miller, "Boron Solubility and Boride Compositions in Two-Phase Titanium Aluminides", Intermetallics, in press.

30. D.J. Larson, C. T. Liu and M. K. Miller, "Tungsten Segregation in $\alpha_{2}+\gamma$ Titanium Aluminides", Intermetallics, in press.

31. M. Yamaguchi and H. Inui, "TiAl Compounds for Structural Applications", Structural Intermetaliics, eds. R. Darolia, J. Lewandowski, C. T. Liu, P. Martin, D. Miracle and M. Nathal, TMS, Warrendale, PA, 1993, p. 127-142.

32. H. Inui, K. Kishida, M. Kobayashi, M. Yamaguchi, M., Kawasaki, and K. Ibe, "Compositional Variations at TiAI-TiAl Lamellar Boundaries in Binary and Some Ternary PST TiAl", Phil. Mag, A, 74 (1996) 451-464. 